\title{
Host-protective effect of circulating pentraxin 3 (PTX3) and complex formation with neutrophil extracellular traps
}

\author{
Kenji Daigo and Takao Hamakubo* \\ Department of Molecular Biology and Medicine, Research Center for Advanced Science and Technology, The University of Tokyo, Tokyo, Japan
}

\section{Edited by:}

Mariana J. Kaplan, University of

Michigan, USA

Reviewed by:

Robert A. Harris, Karolinska

Institutet, Sweden

Martin Herrmann,

Universitätsklinikum Erlangen,

Germany

Min Wu, University of North Dakota, USA

\section{*Correspondence:}

Takao Hamakubo, Department of Molecular Biology and Medicine, Research Center for Advanced Science and Technology, The University of Tokyo, 4-6-1 Komaba, Meguro, Tokyo 153-8904, Japan. e-mail: hamakubo@lsbm.org
Pentraxin 3 (PTX3) is a soluble pattern recognition receptor which is classified as a long-pentraxin in the pentraxin family. It is known to play an important role in innate immunity, inflammatory regulation, and female fertility. PTX3 is synthesized by specific cells, primarily in response to inflammatory signals. Among these various cells, neutrophils have a unique PTX3 production system. Neutrophils store PTX3 in neutrophil-specific granules and then the stored PTX3 is released and localizes in neutrophil extracellular traps (NETs). Although certain NET components have been identified, such as histones and anti-microbial proteins, the detailed mechanisms by which NETs localize, as well as capture and kill microbes, have not been fully elucidated. PTX3 is a candidate diagnostic marker of infection and vascular damage. In severe infectious diseases such as sepsis, the circulating PTX3 concentration increases greatly (up to $100 \mathrm{ng} / \mathrm{mL}$, i.e., up to 100 -fold of the normal level). Even though it is clearly implied that PTX3 plays a protective role in sepsis and certain other disorders, the detailed mechanisms by which it does so remain unclear. A proteomic study of PTX3 ligands in septic patients revealed that PTX3 forms a complex with certain NET component proteins. This suggests a role for PTX3 in which it facilitates the efficiency of anti-microbial protein pathogen clearance by interacting with both pathogens and anti-microbial proteins. We discuss the possible relationships between PTX3 and NET component proteins in the host protection afforded by the innate immune response. The PTX3 complex has the potential to be a highly useful diagnostic marker of sepsis and other inflammatory diseases.

Keywords: PTX3, pentraxin, diagnosis, protein complex, anti-microbial protein, host-protection

\section{INTRODUCTION}

The release of neutrophil extracellular traps (NETs), first reported in 2004 (Brinkmann, 2004), is one of the antimicrobial actions of neutrophils. NETs are mesh-like structures that contain DNA as a backbone, with anti-microbial proteins attached (Amulic and Hayes, 2011). NETs trap microbes and form an anti-microbial-protein-rich microenvironment (Medina, 2009).

Pentraxin 3 (PTX3) was reported as one of the NET component proteins (Jaillon et al., 2007). PTX3 is a member of pentraxin family and mainly acts as a soluble pattern recognition receptor (PRR) in the innate immune response (Bottazzi et al., 2010). In NETs, PTX3 may participate in microbial recognition by facilitating the trapping of microbes. The circulating PTX3 level is known to be increased in certain diseases, and PTX3 may predominantly play a critical role in host protection. Interestingly, proteomic identification of the circulating PTX3 interacting proteins revealed that PTX3 formed a complex with NET component proteins (Daigo et al., 2012). This finding implies that the NET component proteins are active in pathogen recognition and clearance by tethering with each other in NETs and bloodstream. PTX3 appears to be a key tethering molecule to enhance the actions of NETs component proteins. In this review, we will discuss the host-protective roles of PTX3 in relation to NETs component proteins.

\section{NETS}

\section{SOURCE, EXPRESSION, AND FUNCTION}

Neutrophils are the major player in the innate immune system response against microbial pathogen invasion. One of the antimicrobial activities of neutrophils is the extrusion of NETs (Brinkmann, 2004). NETs are formed upon the activation of neutrophils by factors such as IL-8, lipopolysaccharide (LPS), phorbol 12-myristate 13-acetate (PMA), bacteria, fungi, and activated platelets (Brinkmann, 2004; Clark et al., 2007; Fuchs et al., 2007). Neutrophil death as a result of the extrusion of NETs is called "NETosis," which is a cell death pathway distinct from apoptosis or necrosis (Brinkmann and Zychlinsky, 2007; Steinberg and Grinstein, 2007). The release of NETs has also been reportedly observed without cell death (Yipp et al., 2012). Extracellular formations of this type are also observed in basophils and eosinophils (Schorn et al., 2012). NETs are mesh-like structures that consist of cellular DNA, along with bactericidal proteins, that reside in neutrophil granules and the nucleus. These proteins are connected to DNA fibers, and form a specialized microenvironment which facilitates the capture and killing of bacteria. 


\section{THE NET COMPONENT PROTEINS}

Using a proteomic approach, Urban et al. identified 24 NETassociated proteins (Urban et al., 2009). These proteins are; nuclear components such as core histones; granular components such as neutrophil elastase (ELANE), lactotransferrin (LTF), cathepsin G (CTSG), myeloperoxidase (MPO), proteinase 3 (PRTN3), azurocidin 1 (AZU1), lysozyme C (LYZ), neutrophil defensins, and cytoplasmic proteins. In other proteins, histone $\mathrm{H} 1$, bactericidal permeability-increasing protein (BPI), pentraxin 3 (PTX3), and cathelicidin anti-microbial peptide (CAMP) are also defined as NET component proteins (Brinkmann, 2004; Jaillon et al., 2007; Lauth et al., 2009). Essentially all of these proteins possess anti-microbial activity.

\section{PTX3}

\section{GENOME}

Breviario et al. identified PTX3 as one of the IL- $1 \beta$-induced genes in human umbilical vein endothelial cells (HUVECs) (Breviario et al., 1992). The human PTX3 gene is located on chromosome $3 q$ band 25, consists of 1861 base pairs, and is translated into 381 amino acids (Breviario et al., 1992). PTX3 belongs to the pentraxin family, which included the acute phase proteins $\mathrm{C}$-reactive protein (CRP) and serum amyloid P-component (SAP). As PTX3 has a longer $\mathrm{N}$-terminal domain, it is classified as a member of the long-pentraxin subfamily. Unlike the more common short pentraxins CRP and SAP, the PTX3 gene is highly conserved across species (Garlanda et al., 2005). The PTX3 gene consists of three exons, among which the first and second exons encode the signal sequence peptide and the $\mathrm{N}$-terminal domain, and the third exon encodes the C-terminal domain. In the promoter region of the PTX3 gene, a number of potential enhancer binding sequences (Pu-1, AP1, NF-кB, SP1, and NF-IL6) are located (He et al., 2007).

\section{STRUCTURE}

After the processing of the signal sequence of the translated 1-17 amino acids, the mature PTX3 consists of two domains, i.e., the N-terminal domain (18-178 a.a.) and C-terminal domain (179-381 a.a.). The PTX3 C-terminal domain is a pentraxinlike domain, which is conserved among the pentraxin family with pentraxin signature (His-x-Cys-x-Ser/Thr-Trp-x-Ser). An $\mathrm{N}$-linked glycosylation site (Asn220) is located in the C-terminal domain. In contrast to the C-terminal domain, the PTX3 Nterminal domain is a unique sequence unrelated to other proteins. The PTX3 protein forms an octamer via the inter-molecule disulfide bonds (Inforzato et al., 2008, 2010). Briefly, the N-terminal domain participates in the organization of a tetramer, and the $\mathrm{C}$ terminal domain participates in the dimerization of the tetramer. Interestingly, the N-terminal tetramer formation has two states; a tetramer via the inter-disulfide bonds or non-covalent dimerization of the inter-disulfide-bonded dimer. This results in the asymmetric form of the full-length PTX3 (Inforzato et al., 2010).

\section{EXPRESSION PATTERN}

PTX3 mRNA expression is induced by primary inflammatory signals in certain cells, such as myeloid dendritic cells (Doni et al., 2003), peripheral blood leukocytes (Alles et al., 1994), mononuclear macrophages/phagocytes (Alles et al., 1994;
Goodman et al., 2000), vascular endothelial cells (Breviario et al., 1992; Lee et al., 1993), smooth muscle cells (Klouche et al., 2004), fibroblasts (Lee et al., 1993; Goodman et al., 2000), adipocytes (Abderrahim-Ferkoune et al., 2003), glial cells (Polentarutti et al., 2000), cumulus oophorus cells (Salustri et al., 2004), mesangial cells (Nauta et al., 2005), and synovial cells (Luchetti et al., 2000). Transcriptional activation of PTX3 in response to the proinflammatory cytokines TNF $\alpha$ and IL- $1 \beta$ is regulated by NF- $\mathrm{B}$ binding site in the PTX3 promoter (Altmeyer et al., 1995; Basile et al., 1997). Other pathways also regulate PTX3 expression in a cell- and signal-dependent manner. In detail, please refer to the excellent reviews cited (He et al., 2007; Ortega-Hernandez et al., 2009; Deban et al., 2011; Inforzato et al., 2011).

The characteristic PTX3 expression pattern is observed in neutrophils. In mature neutrophils, the PTX3 protein is abundantly present in granules, but PTX3 mRNA expression is not detected. In contrast, PTX3 mRNA expression is observed in progenitor neutrophils, such as promyelocytes and myelocytes/metamyelocytes (Jaillon et al., 2007). As PTX3 protein expression is observed in both neutrophil precursors and mature neutrophils, it is considered that the PTX3 protein is produced during the course of neutrophil maturation and mature neutrophils store it for use-on-demand. Immunostaining revealed that PTX3 is present in neutrophil granules and that it colocalizes with lactoferrin (Jaillon et al., 2007; Savchenko et al., 2011), suggesting that PTX3 localizes to specific granules. The stored PTX3 in neutrophils is released upon E. coli, S. aureus or zymosan stimulation, as well as PMA, ionomycin or $\mathrm{TNF} \alpha$ treatment (Jaillon et al., 2007; Savchenko et al., 2011; Daigo et al., 2012). PTX3 release is not induced by IL- $1 \beta$ or latex bead stimulation (Jaillon et al., 2007). The released PTX3 localizes to NETs and plays a nonredundant role in pathogen resistance. Thus, PTX3 in neutrophils plays a distinctive role in the innate immune response due to its rapid secretion, as well as by its unique pattern of ready-to-use expression and storage.

\section{CIRCULATING LEVELS}

As the pentraxins CRP and SAP are well-known acute phase proteins, PTX3 may also be an acute phase biomarker. Under physiological conditions, the circulating PTX3 level is as low as approximately $2 \mathrm{ng} / \mathrm{mL}$ (Yamasaki et al., 2009). Recently, many studies on the circulating PTX3 level in clinical trials have been reported. These reports indicate that the PTX3 levels are significantly increased in certain infectious, cardiovascular, kidney, and female reproductive system diseases as well as other disorders (summarized in Table 1). In most cases, the PTX3 level correlates with both the severity and survivability of the disorder. In these diseases, the increases can reach up to $10 \sim 100$ times the control level in severe inflammatory and infectious diseases such as sepsis. In the case of sepsis, the plasma PTX3 dramatically increases to a level of up to $100 \mathrm{ng} / \mathrm{mL}$ (Muller et al., 2001) and the increase correlates with mortality (Mauri et al., 2010).

Although not included in Table 1, there are other infectious diseases, such as severe dengue virus infection (Mairuhu et al., 2005) and meningococcal disease (Sprong et al., 2009), in which the PTX3 levels are also increased. The PTX3 plasma concentration is increased in patients with acute myocardial 
Table 1 | Circulating PTX3 levels measurements in clinical trials.

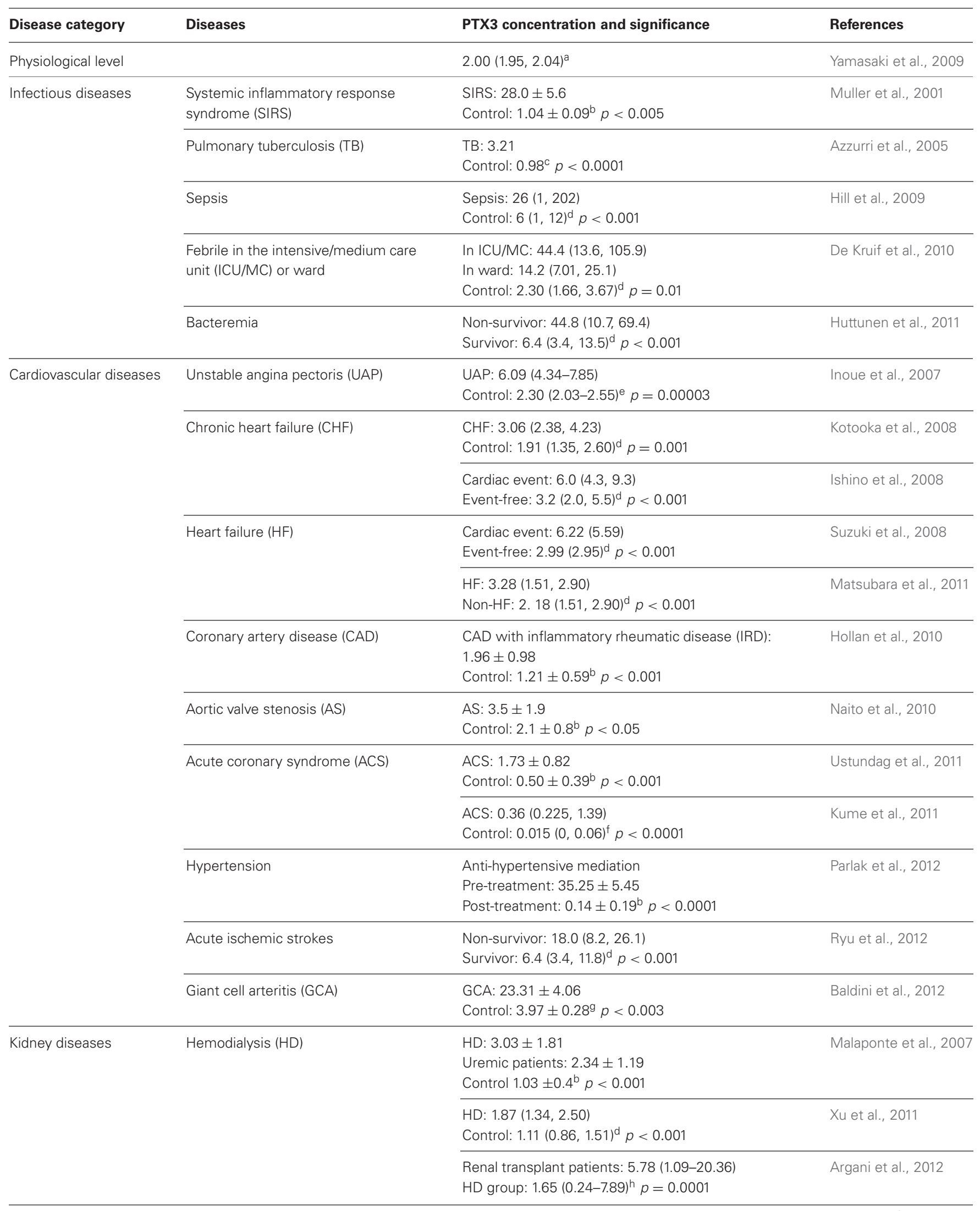


Table 1 | Continued

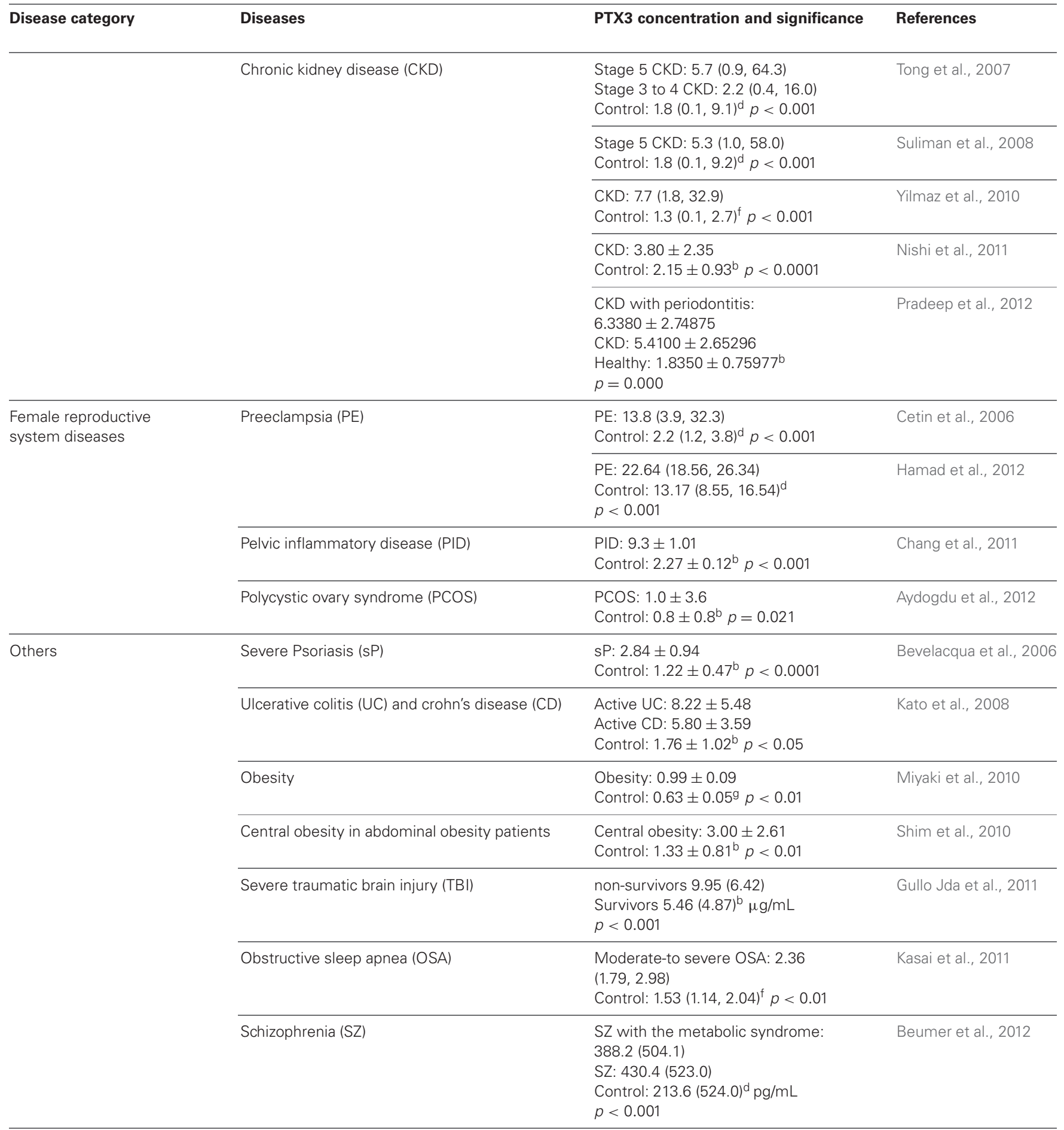

PTX3 concentrations are shown in $\mathrm{ng} / \mathrm{mL}$, unless indicated.

${ }^{a}$ Geometrical mean (confidence interval).

${ }^{b}$ Mean $\pm S D$.

${ }^{\circ}$ Geometrical mean.

${ }^{d}$ Median (interquartile range).

${ }^{e}$ Mean (95\% confidence interval).

${ }^{f}$ Median (25th percentile, 75th percentile).

${ }^{g}$ Mean \pm SEM.

${ }^{h}$ Median (Minimum-Maximum). 
Table 2 | Responses to certain disorders in PTX3-knockout and PTX3-transgenic mice.

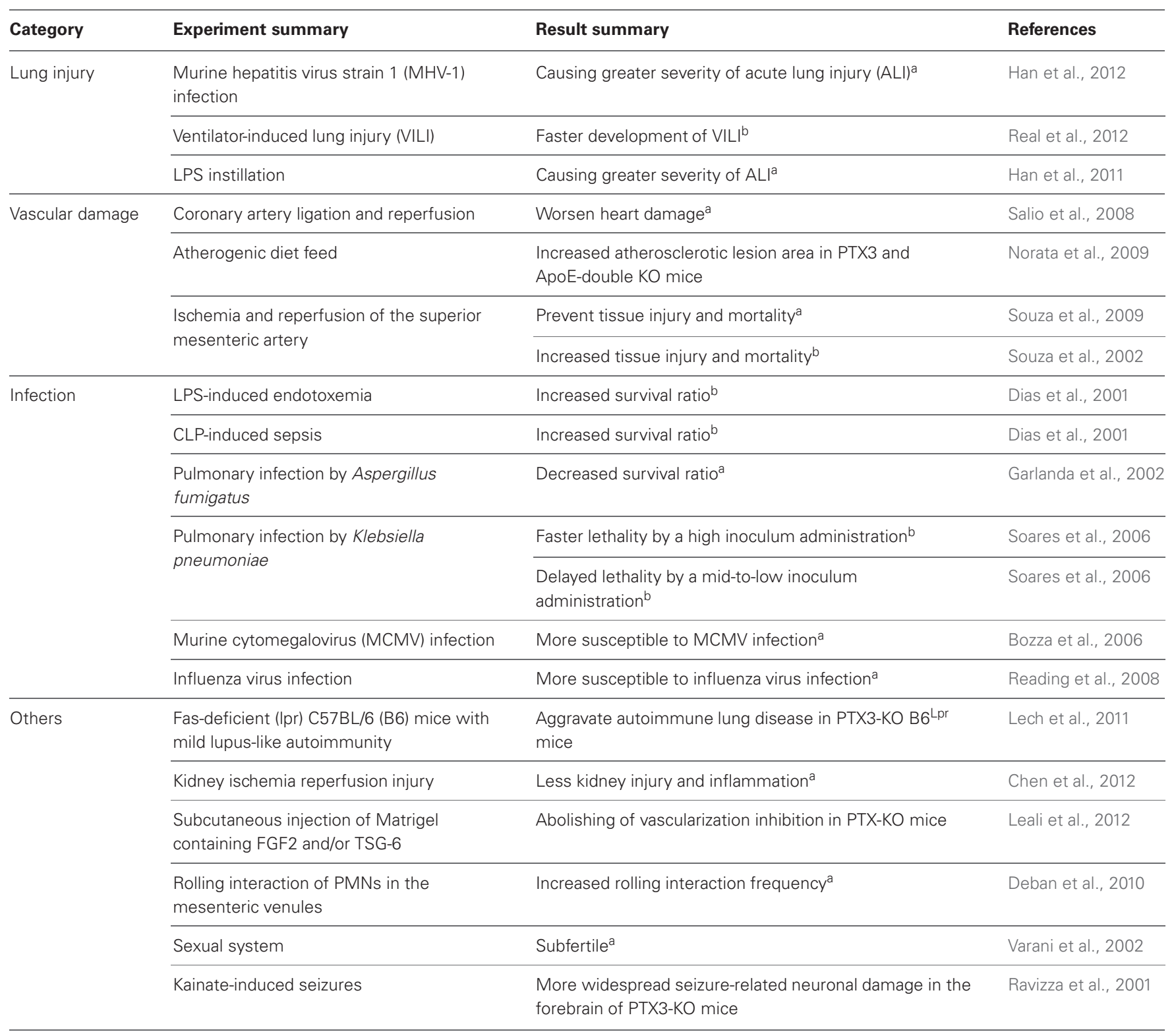

a PTX3-knockout mouse study.

bPTX3-transgenic mouse study.

infarction (Peri et al., 2000). During pregnancy, the serum PTX3 level slightly increases as the pregnancy progresses (Larsson et al., 2011). A higher PTX3 level is observed in preeclampsia (Cetin et al., 2006; Rovere-Querini et al., 2006). Finally, the serum PTX3 level is reported to be a biomarker for lung carcinoma (Diamandis et al., 2011). Thus, the circulating PTX3 level increases nonspecifically in various infections and inflammatory disorders. For the purpose of diagnostic measurement, the dynamics of the PTX3 complex, such as the NET component proteins should be monitored (more details are discussed below).

\section{FUNCTION}

PTX3 has been postulated to play a variety of roles in innate immunity, inflammatory regulation, and female fertility (Bottazzi et al., 2006; Garlanda et al., 2009; Inforzato et al., 2011; Cieslik and Hrycek, 2012). PTX3-knockout and transgenic mice studies have indicated that the predominant role of PTX3 occurs in host protection in the case of lung injury, infection, vascular damage, as well as certain other disorders (summarized in Table 2). Briefly, the resistance against pathogens such as Aspergillus fumigatus, Paracoccidioides brasiliensis, and Klebsiella pneumoniae has been reported (Garlanda et al., 2002; Diniz et al., 2004; Soares et al., 2006). In addition to its anti-pathogenic activity, PTX3 also has been shown to play a role in protecting against severe inflammatory reactions in animal models of sepsis (Dias et al., 2001), seizure-induced neurodegeneration (Ravizza et al., 2001) and acute myocardial infarction (Salio et al., 2008). In addition, PTX3 participates in extracellular matrix deposition. PTX3 is involved 
in the organization of hyaluronan in the viscoelastic matrix of cumulus oophorus (Scarchilli et al., 2007). It is considered that these functions of PTX3 are exhibited synergistically along with the binding of specific ligands (the details are provided in section "Ligands").

Of note, among the studies in PTX3-knockout and transgenic mice, there are some reports of an opposite effect of PTX3 on host-protection. In an intestinal ischemia and reperfusion model, Souza et al. reported an increased injury and lethality in the PTX3-transgenic mice that seemed to be associated with elevation of the TNF $\alpha$ concentration and aggravation of the inflammatory response (Souza et al., 2002). They also reported the suppression of tissue injury and lethality after ischemic and reperfusion in PTX3-knockout mice. PTX3 administration to these PTX3-knockout mice reversed this suppression (Souza et al., 2009). Other groups have also reported an adverse effect of PTX3 in acute ischemic lung injury (Chen et al., 2012) and ventilatorinduced lung injury (Real et al., 2012). In the case of Klebsiella pneumoniae infection, faster lethality was observed when a higher inoculum was administered to PTX3-transgenic mice, but the lethality was conversely delayed when a middle or low inoculum was administered (Soares et al., 2006). Taking these bi-phasic functions of PTX3 in host-defense into account, more detailed accounts of the disease-specific mechanisms of PTX3 need to be elucidated to achieve useful clinical applications.

\section{LIGANDS}

The multiple host-protective functions of PTX3 arise from the capacity for the recognition and binding to ligands. The reported PTX3 ligands are classified as follows: (1) complement components; (2) Fungi, bacteria, microbial components, and viruses; (3) selectin P; (4) extracellular matrix proteins and (5) growth factors (Presta et al., 2007; Mantovani et al., 2008; Deban et al., 2009; Moalli et al., 2011). Some of these ligands bind to PTX3 in a PTX3-domain specific manner, while others require full-length PTX3 for binding (Deban et al., 2009; Bottazzi et al., 2010).

Table 3 | List of the NET component proteins and proteins belonging to the PTX3 complex.

NET component proteins

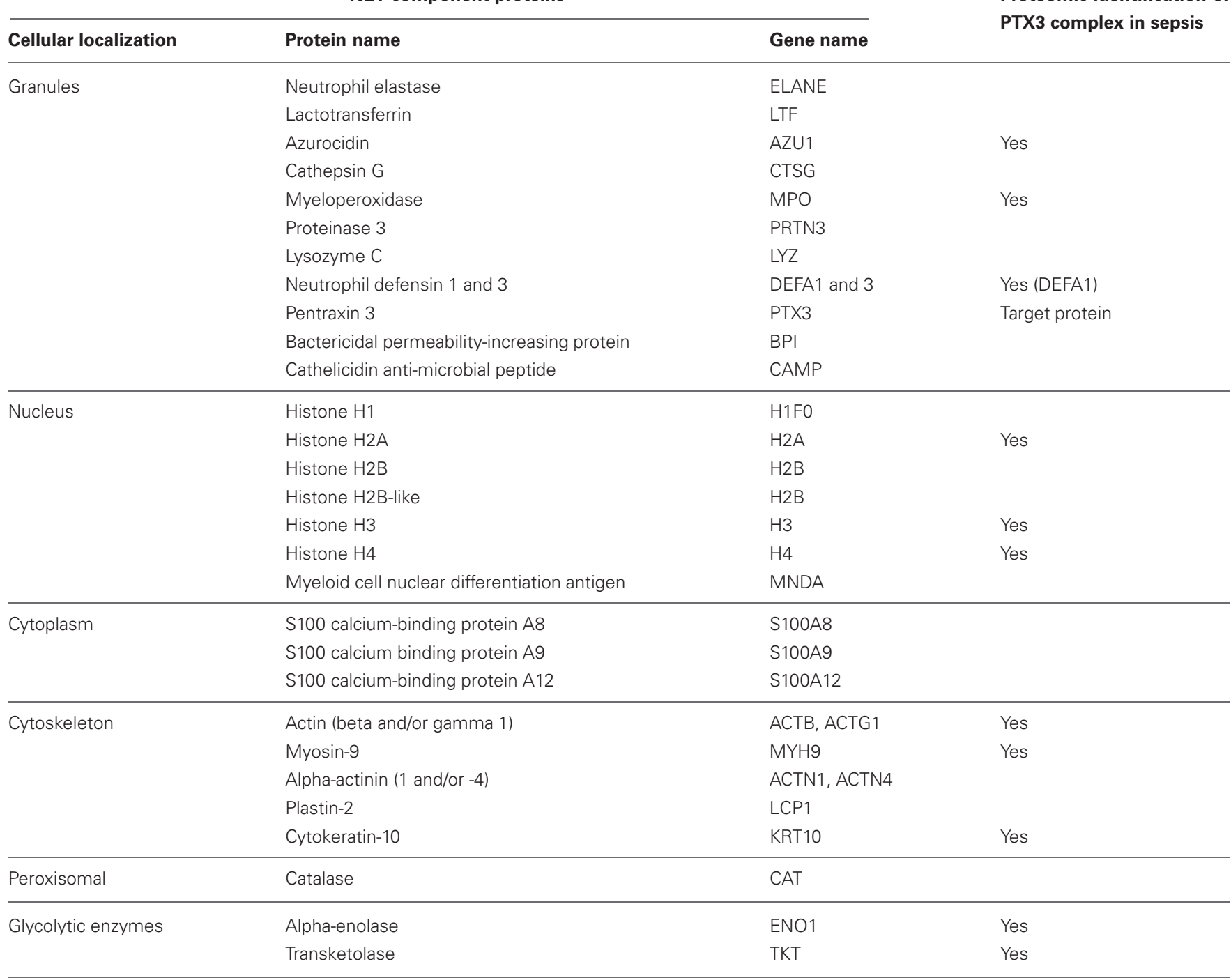


1. PTX3 binds to certain select complement components, such as C1q (Inforzato et al., 2006), C4b-binding proteins (Braunschweig and Józsi, 2011), ficolins (Ma et al., 2009; Gout et al., 2011), mannose-binding lectin 2 (MBL) (Ma et al., 2011), factor H (Deban et al., 2008; Kopp et al., 2012), factor H-like protein 1 (Kopp et al., 2012) and factor H-related protein 1 (Kopp et al., 2012) for the regulation of the complement pathways in the innate immune response. The interaction of PTX3 and C1q elicits a dual consequence in the classical complement pathway. When $\mathrm{Clq}$ binds to immobilized PTX3, the classical complement pathway is activated; however, the binding of C1q to PTX3 in the fluid phase inhibits complement activation (Nauta et al., 2003). PTX3 can also activate the lectin pathway by binding to the ficolins and MBL. PTX3 enhances complement deposition by ficolin-2 on the Aspergillus fumigatus surface (Ma et al., 2009), and PTX3-MBL binding enhanced C4 and C3 deposition as well as the phagocytosis of Candida albicans (Ma et al., 2011). PTX3 is not only involved in complement activation, but also acts as a complement inhibitor to regulate excessive complement activation by binding to $\mathrm{C} 4 \mathrm{~b}$-binding proteins and factor $\mathrm{H}$. Please refer to the review by Doni et al. for more detail (Doni et al., 2012).

2. In the protection afforded against infection, PTX3 recognizes certain fungi, bacteria, microbial moieties, and viruses. PTX3 binds to microbial pathogens such as Pseudomonas aeruginosa (Garlanda et al., 2002), Salmonella typhimurium (Garlanda et al., 2002), Aspergillus fumigatus (Garlanda et al., 2002), and Paracoccidioides brasiliensis (Diniz et al., 2004). PTX3-knockout mice are susceptible to invasive pulmonary aspergillosis due to inappropriate Th1 and Th2-helper-cellmediated resistance (Garlanda et al., 2002). Macrophages from PTX3-transgenic mice exhibit improved phagocytosis of Paracoccidioides brasiliensis as well as an enhancement of the production of nitric oxide (NO) (Diniz et al., 2004). PTX3 also binds to outer membrane protein A from Klebsiella pneumoniae (KpOmpA) in order to modulate the inflammatory response triggered by KpOmpA (Jeannin et al., 2005). PTX3 binds to cytomegalovirus and influenza virus type $A$ for the inhibition of infection (Bozza et al., 2006; Reading et al., 2008). Upon binding to influenza virus, PTX3 exerts anti-viral activity by the inhibition of hemagglutination, the neutralization of virus infectivity and the inhibition of viral neuraminidase (Reading et al., 2008).

3. As an inflammatory modulator, PTX3 binds to selectin P. The $\mathrm{N}$-linked glycosidic moiety of PTX3 contributes to the binding of selectin $\mathrm{P}$, and this binding dampens neutrophil recruitment at the sites of inflammation (Deban et al., 2010). Importantly, in a model of acid-induced acute lung injury, both exogenous PTX3 and endogenously released PTX3 administration suppress neutrophil recruitment (Deban et al., 2010). This suggests a negative feedback role of PTX3 that dampens the excessive neutrophil recruitment via selectin $P$.

4. PTX3 takes part in extracellular matrix formation by binding to TNF $\alpha$-induced protein 6 (TNFAIP6 or TSG-6) and inter$\alpha$-trypsin inhibitor (I $\alpha$ I) (Salustri et al., 2004; Scarchilli et al., 2007; Ievoli et al., 2011). PTX3-knockout mice exhibit a defect in female fertility because of the defects in ovulation (Varani et al., 2002) and the organization of the cumulus oophorus extracellular matrix (Salustri et al., 2004). The PTX3-TSG-6 and PTX3-I $\alpha$ I binding events are considered to be essential for the organization of hyaluronan in the viscoelastic matrix of cumulus oophorus (Inforzato et al., 2011; Moalli et al., 2011).

5. PTX3 binding to fibroblast growth factor 2 (FGF-2) regulates endothelial cell proliferation and angiogenesis, smooth muscle cell (SMC) activation, and intima thickening after arterial injury (Rusnati et al., 2004; Camozzi et al., 2005). PTX3-FGF2 binding can inhibit the proliferation and chemotactic activity of FGF2 in SMCs by interfering with the interaction of the FGF2 and FGF receptors (Camozzi et al., 2005).

Taking these results, it is clear that the protective effects of PTX3 are realized in coordination with specific PTX3 ligands. Therefore, we carried out a proteome-wide identification of PTX3 ligands and complexes in septic patient serum and plasma.

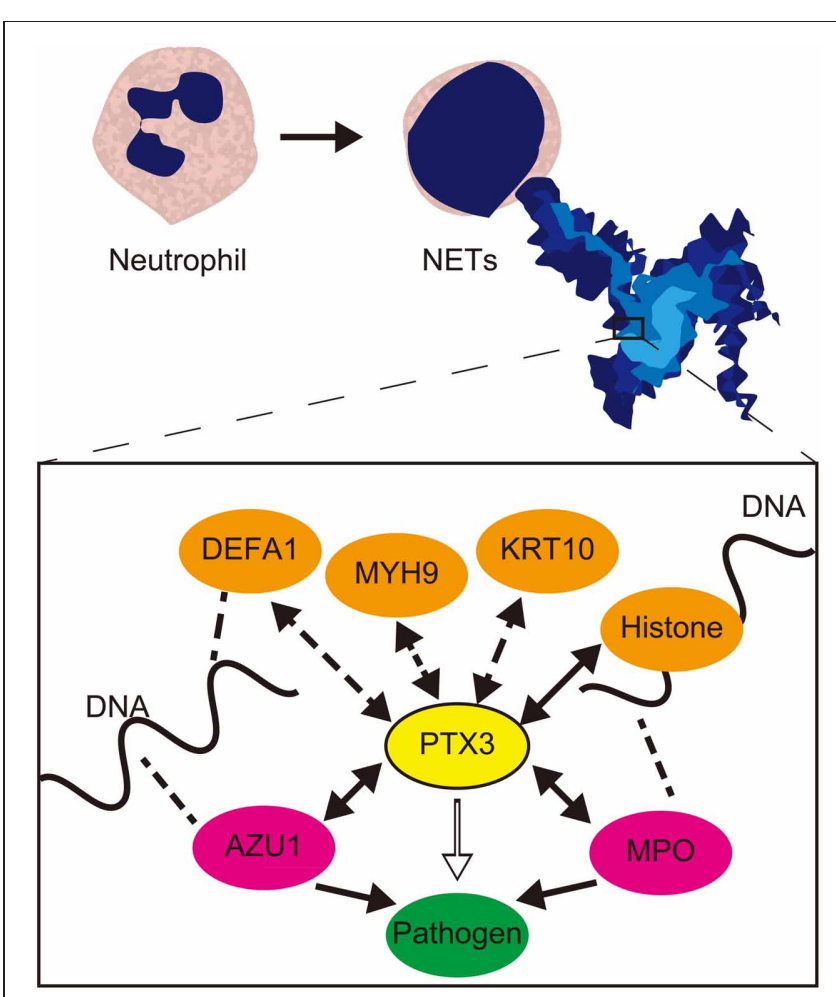

FIGURE 1 | Schematic relationship and role of PTX3 and NET component proteins in pathogen recognition and clearance. NET component proteins which were identified as PTX3 complex (Daigo et al., 2012) are associated PTX3 in NETs. Among these, the confirmed direct interaction of AZU1 and MPO to PTX3, and formerly reported histone-PTX3 interaction (Garlanda et al., 2005) are designated by two-way arrows. These bindings facilitate pathogen clearance efficiency of AZU1 and MPO. The pathogen recognition and anti-pathogenic action are designated by open arrow and closed arrow in box, respectively. Two-way arrows with dashed lines designate other potential interactions to PTX3. The indirect association to DNA via histone or basic proteins such as DEFA1, AZU1, and MPO, which DNA associations are designated by dashed lines, maintains PTX3 localization in NETs. PTX3, pentraxin 3; DEFA1, neutrophil defensin 1; MYH9, Myosn-9; KRT10, Cytokeratin-10; AZU1, azurocidin 1; MPO: myeloperoxidase. 
PTX3 and its complex component proteins were immunoprecipitated by anti-PTX3 antibody-crosslinked magnetic beads, and the isolated fractions were subjected to shotgun proteomics analysis for label-free relative quantitation via spectral counting (Daigo et al., 2012). The identified proteins included the known PTX3 ligands such as C1q, ficolins, TSG-6, and I $\alpha$ I, as mentioned above. Additionally, the ficolin-binding proteins of mannan-binding lectin serine protease 1 and 2 (MASP1 and MASP2) (Ma et al., 2009), and the TSG-6 binding proteins of the versican core protein (VCAN) and thrombospondin-1 (THBS1) (Salustri et al., 2004) were included in the proteins that were identified. As these proteins were identified in pooled normal human plasma with artificially spiked recombinant PTX3, these appear to be stable circulating PTX3 complexes. Nevertheless, the disease-specific dynamics of these binding levels need to be investigated further, as do the specific functions of these PTX3 complexes in sepsis.

\section{NET COMPONENT PROTEINS AS PTX3 LIGANDS: A NEWLY RECOGNIZED PROTECTIVE ROLE}

In the effort to identify the PTX3 ligand in septic patient fluids, a novel finding is that the NET component proteins were included (Daigo et al., 2012) (Table 3). A detailed investigation revealed that azurocidin 1 (AZU1) and myeloperoxidase (MPO) directly bind to PTX3. AZU1 and MPO belong to the NET component proteins (Urban et al., 2009) and exert bactericidal activity (Watorek, 2003; Klebanoff, 2005). AZU1 preferably binds to the PTX3 N-terminal domain, with a pattern of calcium ion dependency. In contrast to AZU1, MPO binds to both the PTX3 N-terminal and C-terminal domains, and does not require calcium ions. Further investigation of the PTX3-AZU1 interaction revealed that the AZU1 binding affinity to PTX3 was $22 \pm$ $7.6 \mathrm{nM}$, and that AZU1 and PTX3 are partially co-localized in NETs (Daigo et al., 2012).

From these results, it is suggested that PTX3 may enhance the bactericidal efficiency of AZU1 and MPO in terms of both pathogen recognition and AZU1 and MPO binding (Figure 1).

\section{REFERENCES}

Abderrahim-Ferkoune, A., Bezy, O., Chiellini, C., Maffei, M., Grimaldi, P., Bonino, F., et al. (2003). Characterization of the long pentraxin PTX3 as a TNFalpha-induced secreted protein of adipose cells. J. Lipid Res. 44, 994-1000.

Alles, V. V., Bottazzi, B., Peri, G., Golay, J., Introna, M., and Mantovani, A. (1994). Inducible expression of PTX3, a new member of the pentraxin family, in human mononuclear phagocytes. Blood 84, 3483-3493.

Altmeyer, A., Klampfer, L., Goodman, A. R., and Vilcek, J. (1995). Promoter structure and transcriptional activation of the murine TSG-14 gene encoding a tumor necrosis factor/interleukin-1inducible pentraxin protein. J. Biol. Chem. 270, 25584-25590.
Amulic, B., and Hayes, G. (2011). Neutrophil extracellular traps. Curr. Biol. 21, R297-R298.

Argani, H., Ghorbanihaghjo, A., Panahi, G., Rashtchizadeh, N., Safa, J., and Meimand, S. M. (2012). Serum Fetuin-A and Pentraxin3 in hemodialysis and renal transplant patients. Clin. Biochem. 45, 775-779.

Aydogdu, A., Tasci, I., Tapan, S., Basaran, Y., Aydogan, U., Meric, C., et al. (2012). High plasma level of long Pentraxin 3 is associated with insulin resistance in women with polycystic ovary syndrome. Gynecol. Endocrinol. 28, 722-725.

Azzurri, A., Sow, O. Y., Amedei, A., Bah, B., Diallo, S., Peri, G., et al. (2005). IFN-gamma-inducible protein 10 and pentraxin 3 plasma levels are tools for monitoring inflammation and disease activity

The mechanism by which PTX3 localizes in NETs has not yet been determined, but it is possible that PTX3 localization arises from an interaction with histones or the basic proteins AZU1, MPO, and defensin, along with a simultaneous association between these basic proteins and DNA (Figure 1). It is not clear at present whether the PTX3-AZU1 and PTX3-MPO binding events in the bloodstream take place within or outside of NETs. Either or even both of these are possible, and these complexes may be active in pathogen recognition and also involved in clearance. In septic patients, the plasma levels of AZU1 are increased, but do not significantly correlate with mortality (Berkestedt et al., 2010). As useful biomarkers of sepsis not yet available (Pierrakos and Vincent, 2010), the binding levels of PTX3-AZU1 and PTX3MPO in septic plasma have the important potential to fulfill this purpose.

\section{CONCLUSION}

Recent proteomic investigation of the circulating PTX3 complex components has revealed new and pivotal roles of PTX3 in the innate immune response, along with a pattern of binding to the NET component proteins. In NETs, PTX3 brings the NET component proteins into close proximity with the pathogens that PTX3 capture in order to enhance pathogen clearance. Also, in the bloodstream, PTX3 forms a complex with bactericidal proteins for the recognition and clearance of pathogens. These activities of PTX3 in concert contribute to the host-protective effect. In addition, the dynamic changes that occur in PTX3 and its complex proteins may become specific biomarker for severe inflammatory diseases.

\section{ACKNOWLEDGMENTS}

This work was supported by Japan Grants-in-Aid for Scientific Research 20221010 from the Ministry of Education, Culture, Sports, Science and Technology, and collaborative research of the University of Tokyo and JSR Corporation. We thank Dr. Kevin Boru of Pacific Edit for review of the manuscript.

in Mycobacterium tuberculosis infection. Microbes Infect. 7, 1-8.

Baldini, M., Maugeri, N., Ramirez, G. A., Giacomassi, C., Castiglioni, A., Prieto-Gonzalez, S., et al. (2012). Selective up-regulation of the soluble pattern-recognition receptor pentraxin 3 and of vascular endothelial growth factor in giant cell arteritis: relevance for recent optic nerve ischemia. Arthritis Rheum. 64, 854-865.

Basile, A., Sica, A., D'Aniello, E., Breviario, F., Garrido, G., Castellano, M., et al. (1997). Characterization of the promoter for the human long pentraxin PTX3. Role of NF-kappaB in tumor necrosis factor-alpha and interleukin-1beta regulation. J. Biol. Chem. 272, 8172-8178.

Berkestedt, I., Herwald, H., Ljunggren, L., Nelson, A., and Bodelsson,
M. (2010). Elevated plasma levels of antimicrobial polypeptides in patients with severe sepsis. J. Innate Immun. 2, 478-482.

Beumer, W., Drexhage, R. C., De Wit, H., Versnel, M. A., Drexhage, H. A., and Cohen, D. (2012). Increased level of serum cytokines, chemokines and adipokines in patients with schizophrenia is associated with disease and metabolic syndrome. Psychoneuroendocrinology 37, 1901-1911.

Bevelacqua, V., Libra, M., Mazzarino, M. C., Gangemi, P., Nicotra, G., Curatolo, S., et al. (2006). Long pentraxin 3: a marker of inflammation in untreated psoriatic patients. Int. J. Mol. Med. 18, 415-423.

Bottazzi, B., Bastone, A., Doni, A., Garlanda, C., Valentino, S., Deban, L., et al. (2006). The long pentraxin 
PTX3 as a link among innate immunity, inflammation, and female fertility. J. Leukoc. Biol. 79, 909-912.

Bottazzi, B., Doni, A., Garlanda, C., and Mantovani, A. (2010). An integrated view of humoral innate immunity: pentraxins as a paradigm. Annu. Rev. Immunol. 28, 157-183.

Bozza, S., Bistoni, F., Gaziano, R., Pitzurra, L., Zelante, T., Bonifazi, P., et al. (2006). Pentraxin 3 protects from MCMV infection and reactivation through TLR sensing pathways leading to IRF3 activation. Blood 108, 3387-3396.

Braunschweig, A., and Józsi, M. (2011). Human pentraxin 3 binds to the complement regulator c4b-binding protein. PLOS ONE 6:e23991. doi: 10.1371/journal.pone.0023991

Breviario, F., D’Aniello, E. M., Golay, J., Peri, G., Bottazzi, B., Bairoch, A., et al. (1992). Interleukin-1inducible genes in endothelial cells. Cloning of a new gene related to Creactive protein and serum amyloid P component. J. Biol. Chem. 267, 22190-22197.

Brinkmann, V. (2004). Neutrophil extracellular traps kill bacteria. Science 303, 1532-1535.

Brinkmann, V., and Zychlinsky, A. (2007). Beneficial suicide: why neutrophils die to make NETs. Nat. Rev. Microbiol. 5, 577-582.

Camozzi, M., Zacchigna, S., Rusnati, M., Coltrini, D., Ramirez-Correa, G., Bottazzi, B., et al. (2005). Pentraxin 3 inhibits fibroblast growth factor 2-dependent activation of smooth muscle cells in vitro and neointima formation in vivo. Arterioscler. Thromb. Vasc. Biol. 25, 1837-1842.

Cetin, I., Cozzi, V., Pasqualini, F., Nebuloni, M., Garlanda, C., Vago, L., et al. (2006). Elevated maternal levels of the long pentraxin 3 (PTX3) in preeclampsia and intrauterine growth restriction. Am. J. Obstet. Gynecol. 194, 1347-1353.

Chang, C. C., Wang, P. H., Su, P. H., Lin, D. B., Ying, T. H., Yang, S. F., et al. (2011). Significant elevation of plasma pentraxin 3 in patients with pelvic inflammatory disease. Clin. Chem. Lab. Med. 49, 1655-1660.

Chen, J., Matzuk, M. M., Zhou, X. J., and Lu, C. Y. (2012). Endothelial pentraxin 3 contributes to murine ischemic acute kidney injury. Kidney Int. 82, 1195-1207.

Cieslik, P., and Hrycek, A. (2012). Long pentraxin 3 (PTX3) in the light of its structure, mechanism of action and clinical implications. Autoimmunity $45,119-128$.
Clark, S. R., Ma, A. C., Tavener, S. A., McDonald, B., Goodarzi, Z. Kelly, M. M., et al. (2007). Platelet TLR4 activates neutrophil extracellular traps to ensnare bacteria in septic blood. Nat. Med. 13, 463-469.

Daigo, K., Yamaguchi, N., Kawamura, T., Matsubara, K., Jiang, S., Ohashi, R., et al. (2012). The proteomic profile of circulating pentraxin 3 (PTX3) complex in sepsis demonstrates the interaction with azurocidin 1 and other components of neutrophil extracellular traps. $\mathrm{Mol}$. Cell Proteomics 11, M111 015073.

Deban, L., Bottazzi, B., Garlanda, C., De La Torre, Y. M., and Mantovani, A. (2009). Pentraxins: multifunctional proteins at the interface of innate immunity and inflammation. Biofactors 35, 138-145.

Deban, L., Jaillon, S., Garlanda, C., Bottazzi, B., and Mantovani, A. (2011). Pentraxins in innate immunity: lessons from PTX3. Cell Tissue Res. 343, 237-249.

Deban, L., Jarva, H., Lehtinen, M. J., Bottazzi, B., Bastone, A., Doni, A., et al. (2008). Binding of the long pentraxin PTX3 to factor $\mathrm{H}$ : interacting domains and function in the regulation of complement activation. J. Immunol. 181, 8433-8440.

Deban, L., Russo, R. C., Sironi, M., Moalli, F., Scanziani, M., Zambelli, V., et al. (2010). Regulation of leukocyte recruitment by the long pentraxin PTX3. Nat. Immunol. 11, 328-334.

De Kruif, M. D., Limper, M., Sierhuis, K., Wagenaar, J. F., Spek, C. A., Garlanda, C., et al. (2010). PTX3 predicts severe disease in febrile patients at the emergency department. J. Infect. 60, 122-127.

Diamandis, E. P., Goodglick, L., Planque, C., and Thornquist, M. D. (2011). Pentraxin-3 is a novel biomarker of lung carcinoma. Clin. Cancer Res. 17, 2395-2399.

Dias, A. A., Goodman, A. R., Dos Santos, J. L., Gomes, R. N., Altmeyer, A., Bozza, P. T., et al. (2001). TSG-14 transgenic mice have improved survival to endotoxemia and to CLP-induced sepsis. J. Leukoc. Biol. 69, 928-936.

Diniz, S. N., Nomizo, R., Cisalpino, P. S., Teixeira, M. M., Brown, G. D., Mantovani, A., et al. (2004). PTX3 function as an opsonin for the dectin-1-dependent internalization of zymosan by macrophages. J. Leukoc. Biol. 75, 649-656.

Doni, A., Garlanda, C., Bottazzi, B., Meri, S., Garred, P., and Mantovani, A. (2012). Interactions of the humoral pattern recognition molecule PTX3 with the complement system. Immunobiology 217 , 1122-1128.

Doni, A., Peri, G., Chieppa, M., Allavena, P., Pasqualini, F., Vago, L., et al. (2003). Production of the soluble pattern recognition receptor PTX3 by myeloid, but not plasmacytoid, dendritic cells. Eur. J. Immunol. 33, 2886-2893.

Fuchs, T. A., Abed, U., Goosmann, C. Hurwitz, R., Schulze, I., Wahn, V. et al. (2007). Novel cell death program leads to neutrophil extracellular traps. J. Cell Biol. 176, 231-241.

Garlanda, C., Bottazzi, B., Bastone, A., and Mantovani, A. (2005) Pentraxins at the crossroads between innate immunity, inflammation, matrix deposition, and female fertility. Annu. Rev. Immunol. 23, 337-366.

Garlanda, C., Hirsch, E., Bozza, S. Salustri, A., De Acetis, M., Nota, R., et al. (2002). Non-redundant role of the long pentraxin PTX3 in antifungal innate immune response. Nature 420, 182-186

Garlanda, C., Maina, V., Cotena, A. and Moalli, F. (2009). The soluble pattern recognition receptor pentraxin-3 in innate immunity, inflammation and fertility. J. Reprod. Immunol. 83, 128-133.

Goodman, A. R., Levy, D. E., Reis, L. F., and Vilcek, J. (2000). Differential regulation of TSG-14 expression in murine fibroblasts and peritoneal macrophages. J. Leukoc. Biol. 67, 387-395.

Gout, E., Moriscot, C., Doni, A. Dumestre-Perard, C., Lacroix, M., Perard, J., et al. (2011). Mficolin interacts with the long pentraxin PTX3: a novel case of cross-talk between soluble patternrecognition molecules. J. Immunol. 186, 5815-5822.

Gullo Jda, S., Bertotti, M. M., Silva, C. C., Schwarzbold, M., Diaz, A. P., Soares, F. M., et al. (2011). Hospital mortality of patients with severe traumatic brain injury is associated with serum PTX3 levels. Neurocrit. Care 14, 194-199.

Hamad, R. R., Eriksson, M. J., Berg, E., Larsson, A., and Bremme, K. (2012). Impaired endothelial function and elevated levels of pentraxin 3 in early-onset preeclampsia. Acta Obstet. Gynecol. Scand. 91, 50-56.

Han, B., Haitsma, J. J., Zhang, Y., Bai, X., Rubacha, M., Keshavjee, S., et al. (2011). Long pentraxin PTX3 deficiency worsens LPS-induced acute lung injury. Intensive Care Med. 37, 334-342.

Han, B., Ma, X., Zhang, J., Zhang, Y., Bai, X., Hwang, D. M., et al. (2012).
Protective effects of long pentraxin PTX3 on lung injury in a severe acute respiratory syndrome model in mice. Lab. Invest. 92, 1285-1296.

He, X., Han, B., and Liu, M. (2007). Long pentraxin 3 in pulmonary infection and acute lung injury. Am. J. Physiol. Lung Cell Mol. Physiol. 292, L1039-L1049.

Hill, A. L., Lowes, D. A., Webster, N. R., Sheth, C. C., Gow, N. A., and Galley, H. F. (2009). Regulation of pentraxin- 3 by antioxidants. $B r$. $J$ Anaesth. 103, 833-839.

Hollan, I., Bottazzi, B., Cuccovillo, I., Forre, O. T., Mikkelsen, K., Saatvedt, K., et al. (2010). Increased levels of serum pentraxin 3, a novel cardiovascular biomarker, in patients with inflammatory rheumatic disease. Arthritis Care Res. (Hoboken) 62, 378-385.

Huttunen, R., Hurme, M., Aittoniemi, J., Huhtala, H., Vuento, R., Laine, J., et al. (2011). High plasma level of long pentraxin 3 (PTX3) is associated with fatal disease in bacteremic patients: a prospective cohort study. PLoS ONE 6:e17653. doi: 10.1371/journal.pone.0017653

Ievoli, E., Lindstedt, R., Inforzato, A., Camaioni, A., Palone, F., Day, A. J., et al. (2011). Implication of the oligomeric state of the N-terminal PTX3 domain in cumulus matrix assembly. Matrix Biol. 30, 330-337.

Inforzato, A., Baldock, C., Jowitt, T. A., Holmes, D. F., Lindstedt, R., Marcellini, M., et al. (2010). The angiogenic inhibitor long pentraxin PTX3 forms an asymmetric octamer with two binding sites for FGF2. J. Biol. Chem. 285, 17681-17692.

Inforzato, A., Jaillon, S., Moalli, F., Barbati, E., Bonavita, E., Bottazzi, B., et al. (2011). The long pentraxin PTX3 at the crossroads between innate immunity and tissue remodelling. Tissue Antigens 77, 271-282.

Inforzato, A., Peri, G., Doni, A., Garlanda, C., Mantovani, A., Bastone, A., et al. (2006). Structure and function of the long pentraxin PTX3 glycosidic moiety: fine-tuning of the interaction with $\mathrm{Clq}$ and complement activation. Biochemistry 45, 11540-11551.

Inforzato, A., Rivieccio, V., Morreale, A. P., Bastone, A., Salustri, A., Scarchilli, L., et al. (2008). Structural characterization of PTX3 disulfide bond network and its multimeric status in cumulus matrix organization. J. Biol. Chem. 283, 10147-10161.

Inoue, K., Sugiyama, A., Reid, P. C., Ito, Y., Miyauchi, K., Mukai, S., et al. (2007). Establishment of a high sensitivity plasma assay for human 
pentraxin3 as a marker for unstable angina pectoris. Arterioscler. Thromb. Vasc. Biol. 27, 161-167.

Ishino, M., Takeishi, Y., Niizeki, T., Watanabe, T., Nitobe, J., Miyamoto, T., et al. (2008). Risk stratification of chronic heart failure patients by multiple biomarkers: implications of BNP, H-FABP, and PTX3. Circ. J. 72, 1800-1805.

Jaillon, S., Peri, G., Delneste, Y., Fremaux, I., Doni, A., Moalli, F., et al. (2007). The humoral pattern recognition receptor PTX3 is stored in neutrophil granules and localizes in extracellular traps. J. Exp. Med. 204, 793-804

Jeannin, P., Bottazzi, B., Sironi, M., Doni, A., Rusnati, M., Presta, M., et al. (2005). Complexity and complementarity of outer membrane protein A recognition by cellular and humoral innate immunity receptors. Immunity 22, 551-560.

Kasai, T., Inoue, K., Kumagai, T., Kato, M., Kawana, F., Sagara, M., et al. (2011). Plasma pentraxin3 and arterial stiffness in men with obstructive sleep apnea. Am. J. Hypertens. 24, 401-407.

Kato, S., Ochiai, M., Sakurada, T., Ohno, S., Miyamoto, K., Sagara, M., et al. (2008). Increased expression of long pentraxin PTX3 in inflammatory bowel diseases. Dig. Dis. Sci. 53, 1910-1916.

Klebanoff, S. J. (2005). Myeloperoxidase: friend and foe. J. Leukoc. Biol. 77, 598-625.

Klouche, M., Peri, G., Knabbe, C., Eckstein, H. H., Schmid, F. X., Schmitz, G., et al. (2004). Modified atherogenic lipoproteins induce expression of pentraxin-3 by human vascular smooth muscle cells. Atherosclerosis 175, 221-228.

Kopp, A., Strobel, S., Tortajada, A., Rodriguez De Cordoba, S., SanchezCorral, P., Prohaszka, Z., et al. (2012). Atypical hemolytic uremic syndrome-associated variants and autoantibodies impair binding of factor $\mathrm{h}$ and factor h-related protein 1 to pentraxin 3. J. Immunol. 189, 1858-1867.

Kotooka, N., Inoue, T., Aoki, S., Anan, M., Komoda, H., and Node, K. (2008). Prognostic value of pentraxin 3 in patients with chronic heart failure. Int. J. Cardiol. 130, 19-22.

Kume, N., Mitsuoka, H., Hayashida, K., and Tanaka, M. (2011). Pentraxin 3 as a biomarker for acute coronary syndrome: comparison with biomarkers for cardiac damage. J. Cardiol. 58, 38-45.

Larsson, A., Palm, M., Helmersson, J., and Axelsson, O. (2011). Pentraxin
3 values during normal pregnancy. Inflammation 34, 448-451.

Lauth, X., Von Kockritz-Blickwede, M., McNamara, C. W., Myskowski, S., Zinkernagel, A. S., Beall, B., et al. (2009). M1 protein allows group A streptococcal survival in phagocyte extracellular traps through cathelicidin inhibition. J. Innate Immun. 1, 202-214.

Leali, D., Inforzato, A., Ronca, R. Bianchi, R., Belleri, M., Coltrini, D., et al. (2012). Long pentraxin 3/tumor necrosis factor-stimulated gene-6 interaction: a biological rheostat for fibroblast growth factor 2-mediated angiogenesis. Arterioscler. Thromb. Vasc. Biol. 32, 696-703.

Lech, M., Rommele, C., Kulkarni, O. P., Susanti, H. E., Migliorini, A., Garlanda, C., et al. (2011). Lack of the long pentraxin PTX3 promotes autoimmune lung disease but not glomerulonephritis in murine systemic lupus erythematosus. PLoS ONE 6:e20118. doi: 10.1371/journal.pone.0020118

Lee, G. W., Lee, T. H., and Vilcek, J. (1993). TSG-14, a tumor necrosis factor- and IL-1-inducible protein, is a novel member of the pentaxin family of acute phase proteins. J. Immunol. 150, 1804-1812.

Luchetti, M. M., Piccinini, G., Mantovani, A., Peri, G., Matteucci, C., Pomponio, G., et al. (2000). Expression and production of the long pentraxin PTX3 in rheumatoid arthritis (RA). Clin. Exp. Immunol. 119, 196-202.

Mairuhu, A. T., Peri, G., Setiati, T. E., Hack, C. E., Koraka, P., Soemantri A., et al. (2005). Elevated plasma levels of the long pentraxin, pentraxin 3, in severe dengue virus infections. J. Med. Virol. 76, 547-552.

Malaponte, G., Libra, M., Bevelacqua, Y., Merito, P., Fatuzzo, P., Rapisarda, F., et al. (2007). Inflammatory status in patients with chronic renal failure: the role of PTX3 and proinflammatory cytokines. Int. J. Mol. Med. 20, 471-481.

Mantovani, A., Garlanda, C., Doni, A., and Bottazzi, B. (2008). Pentraxins in innate immunity: from C-reactive protein to the long pentraxin PTX3. J. Clin. Immunol. 28, 1-13.

Matsubara, J., Sugiyama, S., Nozaki, T. Sugamura, K., Konishi, M., Ohba, K., et al. (2011). Pentraxin 3 is a new inflammatory marker correlated with left ventricular diastolic dysfunction and heart failure with normal ejection fraction. J. Am. Coll. Cardiol. 57, 861-869.
Mauri, T., Bellani, G., Patroniti, N. Coppadoro, A., Peri, G., Cuccovillo, I., et al. (2010). Persisting high levels of plasma pentraxin 3 over the first days after severe sepsis and septic shock onset are associated with mortality. Intensive Care Med. 36, 621-629.

Ma, Y. J., Doni, A., Hummelshoj, T., Honore, C., Bastone, A., Mantovani, A., et al. (2009). Synergy between ficolin-2 and pentraxin 3 boosts innate immune recognition and complement deposition. J. Biol. Chem. 284, 28263-28275.

Ma, Y. J., Doni, A., Skjoedt, M. O., Honore, C., Arendrup, M., Mantovani, A., et al. (2011) Heterocomplexes of mannosebinding lectin and the pentraxins PTX3 or serum amyloid P component trigger cross-activation of the complement system. J. Biol. Chem. 286, 3405-3417.

Medina, E. (2009). Neutrophil extracellular traps: a strategic tactic to defeat pathogens with potential consequences for the host. J. Innate Immun. 1, 176-180.

Miyaki, A., Maeda, S., Yoshizawa, M. Misono, M., Sasai, H., Shimojo, N., et al. (2010). Is pentraxin 3 involved in obesity-induced decrease in arterial distensibility? J. Atheroscler. Thromb. 17, 278-284.

Moalli, F., Jaillon, S., Inforzato, A. Sironi, M., Bottazzi, B., Mantovani, A., et al. (2011). Pathogen recognition by the long pentraxin PTX3 J. Biomed. Biotechnol. 2011, 830421.

Muller, B., Peri, G., Doni, A., Torri, V., Landmann, R., Bottazzi, B., et al. (2001). Circulating levels of the long pentraxin PTX3 correlate with severity of infection in critically ill patients. Crit. Care Med. 29, 1404-1407.

Naito, Y., Tsujino, T., Akahori, H., Ohyanagi, M., Mitsuno, M. Miyamoto, Y., et al. (2010). Increase in tissue and circulating pentraxin 3 levels in patients with aortic valve stenosis. Am. Heart J. 160, 685-691.

Nauta, A. J., Bottazzi, B., Mantovani, A., Salvatori, G., Kishore, U., Schwaeble, W. J., et al. (2003). Biochemical and functional characterization of the interaction between pentraxin 3 and C1q. Eur. J. Immunol. 33, 465-473.

Nauta, A. J., De Haij, S., Bottazzi, B. Mantovani, A., Borrias, M. C., Aten, J., et al. (2005). Human renal epithelial cells produce the long pentraxin PTX3. Kidney Int. 67, 543-553.

Nishi, K., Imamura, T., Kitamura, K., Ogawa, T., Fujimoto, S., Kakitsubata, Y., et al. (2011) Associations of plasma pentraxin
3 and monocyte chemoattractant protein-1 concentrations with cardiovascular disease in patients with chronic kidney disease. Ren. Fail. 33, 398-404.

Norata, G. D., Marchesi, P., Pulakazhi Venu, V. K., Pasqualini, F., Anselmo, A., Moalli, F., et al. (2009). Deficiency of the long pentraxin PTX3 promotes vascular inflammation and atherosclerosis. Circulation 120, 699-708.

Ortega-Hernandez, O. D., Bassi, N., Shoenfeld, Y., and Anaya, J. M. (2009). The long pentraxin 3 and its role in autoimmunity. Sem. Arthritis Rheum. 39, 38-54.

Parlak, A., Iyisoy, A., Aydogan, U., Cakir, E., and Saglam, K. (2012). The effect of valsartan and nebivolol treatment on ADMA and pentraxin-3 levels in hypertensive patients. Med. Hypotheses 79, 294-298.

Peri, G., Introna, M., Corradi, D., Iacuitti, G., Signorini, S., Avanzini, F., et al. (2000). PTX3, A prototypical long pentraxin, is an early indicator of acute myocardial infarction in humans. Circulation 102, 636-641.

Pierrakos, C., and Vincent, J. L. (2010). Sepsis biomarkers: a review. Crit. Care 14, R15.

Polentarutti, N., Bottazzi, B., Di Santo, E., Blasi, E., Agnello, D., Ghezzi, P., et al. (2000). Inducible expression of the long pentraxin PTX3 in the central nervous system. J. Neuroimmunol. 106, 87-94.

Pradeep, A. R., Kathariya, R., Arjun Raju, P., Sushma Rani, R., Sharma, A., and Raghavendra, N. M. (2012). Risk factors for chronic kidney diseases may include periodontal diseases, as estimated by the correlations of plasma pentraxin-3 levels: a case-control study. Int. Urol. Nephrol. 44, 829-839.

Presta, M., Camozzi, M., Salvatori, G., and Rusnati, M. (2007). Role of the soluble pattern recognition receptor PTX3 in vascular biology. J. Cell. Mol. Med. 11, 723-738.

Ravizza, T., Moneta, D., Bottazzi, B. Peri, G., Garlanda, C., Hirsch, E., et al. (2001). Dynamic induction of the long pentraxin PTX3 in the CNS after limbic seizures: evidence for a protective role in seizure-induced neurodegeneration. Neuroscience 105, 43-53.

Reading, P. C., Bozza, S., Gilbertson, B., Tate, M., Moretti, S., Job, E. R. et al. (2008). Antiviral activity of the long chain pentraxin PTX3 against influenza viruses. J. Immunol. 180, 3391-3398. 
Real, J. M., Spilborghs, G. M., MoratoMarques, M., De Moura, R. P., Negri, E. M., Camargo, A. A., et al. (2012). Pentraxin 3 accelerates lung injury in high tidal volume ventilation in mice. Mol. Immunol. 51, 82-90.

Rovere-Querini, P., Antonacci, S., Dell'Antonio, G., Angeli, A., Almirante, G., Cin, E. D., et al. (2006). Plasma and tissue expression of the long pentraxin 3 during normal pregnancy and preeclampsia. Obstet. Gynecol. 108, 148-155.

Rusnati, M., Camozzi, M., Moroni, E., Bottazzi, B., Peri, G., Indraccolo, S., et al. (2004). Selective recognition of fibroblast growth factor- 2 by the long pentraxin PTX 3 inhibits angiogenesis. Blood 104, 92-99.

Ryu, W. S., Kim, C. K., Kim, B. J., Kim, C., Lee, S. H., and Yoon, B. W. (2012). Pentraxin 3: a novel and independent prognostic marker in ischemic stroke. Atherosclerosis 220, 581-586.

Salio, M., Chimenti, S., De Angelis, N., Molla, F., Maina, V., Nebuloni, M., et al. (2008). Cardioprotective function of the long pentraxin PTX3 in acute myocardial infarction. Circulation 117, 1055-1064.

Salustri, A., Garlanda, C., Hirsch, E., De Acetis, M., Maccagno, A., Bottazzi, B., et al. (2004). PTX3 plays a key role in the organization of the cumulus oophorus extracellular matrix and in in vivo fertilization. Development 131, 1577-1586.

Savchenko, A. S., Inoue, A., Ohashi, R., Jiang, S., Hasegawa, G., Tanaka, T., et al. (2011). Long pentraxin 3 (PTX3) expression and release by neutrophils in vitro and in ulcerative colitis. Pathol. Int. 61, 290-297.

Scarchilli, L., Camaioni, A., Bottazzi, B., Negri, V., Doni, A., Deban, L., et al. (2007). PTX3 interacts with inter-alpha-trypsin inhibitor: implications for hyaluronan organization and cumulus oophorus expansion. J. Biol. Chem. 282, 30161-30170.
Schorn, C., Janko, C., Latzko, M., Chaurio, R., Schett, G., and Herrmann, M. (2012). Monosodium urate crystals induce extracellular DNA traps in neutrophils, eosinophils, and basophils but not in mononuclear cells. Front. Immunol. 3:277. doi 10.3389/fimmu.2012.00277

Shim, B. J., Jeon, H. K., Lee, S. J., Kim, S. S., Park, M. Y., Lee, D. H., et al. (2010). The relationship between serum pentraxin 3 and central obesity in ST-segment elevation myocardial infarction patients. Korean Circ. J. 40, 308-313.

Soares, A. C., Souza, D. G., Pinho, V., Vieira, A. T., Nicoli, J. R., Cunha, F. Q., et al. (2006). Dual function of the long pentraxin PTX3 in resistance against pulmonary infection with Klebsiella pneumoniae in transgenic mice. Microbes Infect. 8, 1321-1329.

Souza, D. G., Amaral, F. A., Fagundes, C. T., Coelho, F. M., Arantes, R. M., Sousa, L. P., et al. (2009). The long pentraxin PTX3 is crucial for tissue inflammation after intestinal ischemia and reperfusion in mice. Am. J. Pathol. 174, 1309-1318.

Souza, D. G., Soares, A. C., Pinho, V., Torloni, H., Reis, L. F., Teixeira, M. M., et al. (2002). Increased mortality and inflammation in tumor necrosis factor-stimulated gene-14 transgenic mice after ischemia and reperfusion injury. Am. J. Pathol. 160, 1755-1765.

Sprong, T., Peri, G., Neeleman, C., Mantovani, A., Signorini, S., Van Der Meer, J. W., et al. (2009). Pentraxin 3 and C-reactive protein in severe meningococcal disease. Shock 31, 28-32.

Steinberg, B. E., and Grinstein, S. (2007). Unconventional roles of the NADPH oxidase: signaling, ion homeostasis, and cell death. Sci. STKE 2007, pe11.

Suliman, M. E., Yilmaz, M. I., Carrero, J. J., Qureshi, A. R., Saglam, M., Ipcioglu, O. M., et al. (2008). Novel links between the long pentraxin 3 , endothelial dysfunction, and albuminuria in early and advanced chronic kidney disease. Clin. J. Am. Soc. Nephrol. 3, 976-985.

Suzuki, S., Takeishi, Y., Niizeki, T., Koyama, Y., Kitahara, T., Sasaki, T., et al. (2008). Pentraxin 3 , a new marker for vascular inflammation, predicts adverse clinical outcomes in patients with heart failure. Am. Heart J. 155 75-81.

Tong, M., Carrero, J. J., Qureshi, A. R., Anderstam, B., Heimburger, O, Barany, P., et al. (2007). Plasma pentraxin 3 in patients with chronic kidney disease: associations with renal function, protein-energy wasting, cardiovascular disease, and mortality. Clin. J. Am. Soc. Nephrol. 2, 889-897.

Urban, C. F., Ermert, D., Schmid, M., Abu-Abed, U., Goosmann, C., Nacken, W., et al. (2009). Neutrophil extracellular traps contain calprotectin, a cytosolic protein complex involved in host defense against Candida albicans. PLoS Pathog. 5:e1000639. doi 10.1371/journal.ppat.1000639

Ustundag, M., Orak, M., Guloglu, C. Sayhan, M. B., Alyan, O., and Kale, E. (2011). Comparative diagnostic accuracy of serum levels of neutrophil activating peptide- 2 and pentraxin-3 versus troponin-I in acute coronary syndrome. Anadolu Kardiyol. Derg. 11, 588-594.

Varani, S., Elvin, J. A., Yan, C., Demayo, J., Demayo, F. J., Horton, H. F., et al. (2002). Knockout of pentraxin 3, a downstream target of growth differentiation factor-9, causes female subfertility. Mol. Endocrinol. 16, 1154-1167.

Watorek, W. (2003). Azurocidin - inactive serine proteinase homolog acting as a multifunctional inflammatory mediator. Acta Biochim. Pol. 50 743-752.

Xu, Y., Ding, X., Zou, J., Liu, Z., Jiang, S., Xu, S., et al. (2011). Plasma pentraxin 3 is associated with cardiovascular disease in hemodialysis patients. Ren. Fail. 33, 998-1004.
Yamasaki, K., Kurimura, M., Kasai, T., Sagara, M., Kodama, T., and Inoue, K. (2009). Determination of physiological plasma pentraxin 3 (PTX3) levels in healthy populations. Clin. Chem. Lab. Med. 47, 471-477.

Yilmaz, M. I., Carrero, J. J., MartinVentura, J. L., Sonmez, A., Saglam, M., Celik, T., et al. (2010). Combined therapy with reninangiotensin system and calcium channel blockers in type 2 diabetic hypertensive patients with proteinuria: effects on soluble TWEAK, PTX3, and flow-mediated dilation. Clin. J. Am. Soc. Nephrol. 5, 1174-1181.

Yipp, B. G., Petri, B., Salina, D., Jenne, C. N., Scott, B. N., Zbytnuik, L. D., et al. (2012). Infection-induced NETosis is a dynamic process involving neutrophil multitasking in vivo. Nat. Med. 18, 1386-1393.

Conflict of Interest Statement: The authors declare that the research was conducted in the absence of any commercial or financial relationships that could be construed as a potential conflict of interest.

Received: 28 September 2012; paper pending published: 16 October 2012; accepted: 26 November 2012; published online: 13 December 2012.

Citation: Daigo $K$ and Hamakubo $T$ (2012) Host-protective effect of circulating pentraxin 3 (PTX3) and complex formation with neutrophil extracellular traps. Front. Immun. 3:378. doi: 10.3389/fimmu. 2012.00378

This article was submitted to Frontiers in Molecular Innate Immunity, a specialty of Frontiers in Immunology. Copyright (c) 2012 Daigo and Hamakubo. This is an open-access article distributed under the terms of the Creative Commons Attribution License, which permits use, distribution and reproduction in other forums, provided the original authors and source are credited and subject to any copyright notices concerning any third-party graphics etc. 